\title{
Supporting Children with Complex Communication Needs
}

Aurora Constantin

University of Edinburgh

10 Crichton St

Edinburgh, EH8 9AB, UK

A.Constantin-2@sms.ed.ac.uk

Permission to make digital or hard copies of all or part of this work for personal or classroom use is granted without fee provided that copies are not made or distributed for profit or commercial advantage and that copies bear this notice and the full citation on the first page. To copy otherwise, or republish, to post on servers or to redistribute to lists, requires prior specific permission and/or a fee.

\begin{abstract}
Children with complex communication needs (CCN) are dramatically restricted in their chances to participate in educational, family, and community environments. Research shows that interactive technologies can bring benefits for children with CCN. This paper briefly presents my experience in developing an authoring tool for supporting practitioners to enhance social communication skills in children with Autism Spectrum Conditions (ASC). Based on this experience, I expose my motivation to participate in "Supporting Children with Complex Communication Needs" workshop, my contributions to the workshop and also my expectations from this workshop.
\end{abstract}

\section{Author Keywords}

Complex communication needs, assistive technologies

\section{ACM Classification Keywords}

H.5.m. Information interfaces and presentation (e.g., $\mathrm{HCI}$ ): Miscellaneous.

\section{Introduction}

Many children with developmental disabilities, such as Autism Spectrum Conditions (ASC), do not develop their communication skills. Research brings strong evidence that appropriate communication support is beneficial for children with complex communication 


\section{Using my Hands} I use my hands for a lot of things (descriptive).

I use my hands to build Lego (descriptive).

When I get cross I used my hands to hit people (descriptive).

This will make people sad

(perspective).

When I am cross I should try to use words instead (control).

Using words will make everyone happy (perspective).

Figure 1: Example of social story collected in the first exploratory study

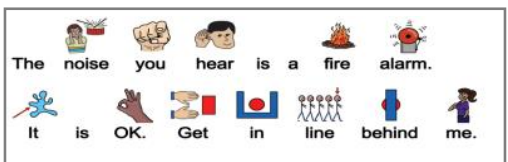

Figure 2: Excerpt from a social story with symbols -retrieved from www.slatersoftware.com/autism.htm needs (CCN) [1]. There is evidence that interactive technologies that address $\mathrm{CCN}$ have a positive impact on children's communication skills [2], without preventing their speech development [3]. However, it is stringently necessary to explore how these technologies can be improved to effectively meet children's needs and interests, and find out ways to ensure that they are incorporated into everyday lives of children with CCN. According to Alper et al.: "researchers and practitioners with a variety of expertise need to work together to develop practical solutions with a chance of succeeding in real-world environments." [4, p 363]

\section{ISISS: an Authoring Tool for Social Story}

\section{Interventions}

Children with ASC have difficulties in developing social communication skills. Social stories are a wide spread intervention which addresses these difficulties (see examples in Fig 1 and Fig 2). The concept of social story was introduced by Carol Gray and defined as a short story with a specific style and format that describes a situation, a social skill, or a concept [5].

Based on an iterative, highly Participatory Design (PD) approach, I have designed, implemented and evaluated an authoring tool to support practitioners in writing, presenting and assessing social stories as a part of my PhD work. ISISS (Improving Social Interaction through Social Stories) is an authoring tool based on theory, research and practice in autism [6]. This has evolved through PD, involving practitioners (teachers, nursery nurses, and speech and language therapists) and experts in Human-Computer Interaction (HCI) in three main stages:
I. exploring current practice in developing social stories;

II. exploring alternative low-fidelity authoring tool prototypes;

III. formative evaluation with high-fidelity authoring tool prototype.

The first exploratory study with practitioners has led to a conceptual framework for social story interventions. It permitted me to identify an initial set of requirements, along with a set of design principles to guide the design of tools to support social story development. According to these requirements and design principles, a set of low-fidelity prototypes were created and then explored in a second study with practitioners. Following the two initial studies, an evolutionary working prototype was developed. This prototype has been iteratively evaluated and refined. The formative evaluations involved practitioners with experience in developing social stories for children with ASC and experts in HCI. ISISS shows promise to be a valuable tool for practitioners in reducing their workload, customizing social stories and engaging the child with the story.

\section{My Reasons for Participation}

Developing educational and assistive technologies involves interdisciplinary knowledge and collaboration. Therefore, it is crucial for a researcher to interact with researchers with similar interests, with various backgrounds and high expertise in designing, implementing and/or evaluating technologies for children with special needs. I am interested in networking with other researchers all around the world. In addition, my presence in this workshop gives me the opportunity to share my experience in developing 
technology for children with special needs (specifically for children with ASC) with other participants.

\section{My Contributions}

My knowledge and experience that I find relevant for this workshop include the following:

- designing and implementing technologies for children with ASC and for practitioners who work with these children;

- $\quad$ evaluation methods for technologies which addressed children with ASC and practitioners;

- $\quad$ insights into specific challenges faced by children with ASC in communication;

- $\quad$ insights into challenges faced by practitioners who work with children with ASC;

- $\quad$ grounded theory methods applied in informing the design of computer-based technologies;

- coding methods in qualitative analysis;

- participatory design and user-centered design approaches;

- action research;

- Human-Computer Interaction;

- $\quad$ prototyping

\section{My Expectations}

I expect that my attendance at "Supporting Children with Complex Communication Needs" workshop will offer me the opportunity to improve my knowledge about the state-of-the-art and the future research directions in the interactive technologies for CCN. I wish that during this workshop I can learn from the other researchers about their successes, limitations and challenges while designing, implementing and evaluating technologies for children with various needs. I also expect that this workshop will help me get valuable insights into specific methods for evaluating interactive technologies. During the workshop I want to create professional relationships with researchers with various backgrounds, and to put the basis of future collaborations. I am firmly convinced that learning from experts and stakeholders concerned with supporting children with $\mathrm{CCN}$ will be an invaluable gain for my PhD work and for my future career.

\section{References}

[1] Wendt, O. Research on the use of manual signs and graphic symbols in autism spectrum disorders: A systematic review. In P. Mirenda \& T. Iacono (Eds.), Autism spectrum disorders and AAC, Baltimore, MD: Brookes (2009), 83-140.

[2] Light J., McNaughton D. Supporting the Communication, Language, and Literacy Development of Children with Complex Communication Needs: State of the Science and Future Research Priorities. Assistive Technology, 24 (2012), 34-44.

[3] Schlosser, R. W., \& Wendt, O. Effects of augmentative and alternative communication intervention on speech production in children with autism: A systematic review. American Journal of Speech-Language Pathology, 17 (2008), 212-230.

[4] Alper, M., Hourcade, J.P. and Gilutz, S.

(2012). Interactive technologies for children with special needs. In Proceedings of IDC (2012), 363-366.

[5] Gray, C. Social Stories 10.0. Jenison Autism Journal, 15, 4 (2004), 2-21.

[6] Constantin, A., Pain, H., Waller, A. Informing the Design of an Authoring Tool for Developing Social Stories. In Proceedings for the 14th IFIP TC13 Conference on HCI, INTERACT 2013, Cape Town, South Africa, Springer (2013), 546-553. 